\title{
Fundamentos jurídicos, límites y control de la actividad de los bancos de los estados federados en la república federal de Alemania**
}

\author{
Andreas Rietzler** \\ Recibido: 15 de mayo de $2014 \cdot$ Revisado: 25 de mayo 2014 \\ Aprobado: 1 de junio de 2014.
}

\section{Resumen}

Este artículo presenta una síntesis de los elementos jurídicos fundamentales del sistema de los bancos de los estados federados en la República Federal de Alemania. Al margen de lo anterior serán tratadas las influencias del derecho de la Unión Europea en la mencionada temática.

Dentro de los principales tipos de trabajos de investigación se encuentran los trabajos de síntesis, los cuales tratan de poner de manifiesto la totalidad del contenido de una materia o tema, exponiendo sus partes principales y esenciales. Dicho tipo de trabajo de investigacion es el que se desarrollará en las siguientes páginas.

Palabras clave: bancos de los estados federados en Alemania, establecimiento público, vigilancia y control.

"El artículo es producto del proyecto de investigación: Elementos jurídicos fundamentales del sistema de bancos de los estados federados en la República Federal de Alemania, el cual es liderado por el autor atendiendo a su calidad de investigador -docente en la Universidad de Konstanz-Alemania. El mencionado proyecto de investigación es financiado por la mencionada Universidad.

"El autor es doctor en Derecho Público y Derecho Administrativo de la Universidad de Konstanz. Asistente de la cátedra de los profesores Wolfgang Heinz y Martin Ibler, docentes de la Universidad de Konstanz-Alemania. Adicionalmente, el autor es profesor de la maestría en Derecho Público de la Universidad Santo Tomás (sede Bogotá). Correo electrónico: andreas.Rietzler@uni-konstanz.de 


\title{
LEGAL GROUNDS, LIMITS AND CONTROLS TO THE ACTIVITIES OF THE BANKS IN THE FEDERAL STATES OF THE FEDERAL REPUbLIC OF GERMANY
}

\begin{abstract}
Abstact
This article presents a synthesis of the fundamental legal elements of the system of banks federados states in the Federal Republic of Germany. Apart from the above will be treated the influences of European Union law on the subject mentioned.

Among the main types of research are the work of synthesis, which tries to reveal the entire contents of a subject or topic, exposing its main and essential parts. This type of research work is to be held on the following pages.
\end{abstract}

Keywords: Banks of the federal states in Germany, public establishment, monitoring and control.

\section{Fundamentos JURídicos, LiMites E CONTROLE DA ATIVIDA \\ DE DOS BANCOS DOS ESTADOS FEDERADOS NA república federal da Alemanha.}

\section{Resumo}

Este artigo apresenta uma síntese dos elementos jurídicos fundamentais do sistema dos bancos dos estados federados da República Federal da Alemanha. Para além do referido serão tratadas as influências do direito da União Europeia sobre $\mathrm{o}$ assunto mencionado.

Entre os principais tipos de pesquisa encontra-se os trabalhos de síntese, os quais tentam revelar todo o conteúdo de um tema ou assunto, expondo as suas partes principais e essenciais. Este tipo de trabalho de investigação está a ser realizado nas páginas seguintes.

Palavras-chave: bancos dos estados federais na Alemanha, estabelecimento público, vigilancia e controle. 


\section{Introducción}

Muchos bancos europeos sufrieron pérdidas inusualmente altas en el contexto de la crisis financiera de los Estados Unidos. Estas pérdidas fueron la consecuencia de un nuevo tipo de negocio (Lutter, 2009, p. 786; Sachverständigenrat, 2008, p. $125)^{1}$. Explicado de manera muy simple: ante todo, bancos norteamericanos amarraron créditos de construcción asegurados con hipotecas, expidieron certificados de crédito sobre ellos y los vendieron a otros bancos. De esta manera, dichos títulos tenían como fundamento las acreencias hipotecarias frente a muchos constructores de viviendas. La ventaja de estos títulos radicaba en unos altos intereses, ya que los intereses hipotecarios, por regla general, son más altos que, por ejemplo, los de títulos de deuda pública. Por otro lado, el riesgo consistía en la insolvencia del deudor "amarrado". Precisamente este escenario fue el que finalmente ocurrió. Los títulos que alguna vez fueron tan codiciados se convirtieron en imposibles de vender y con ello perdieron todo su valor. Dentro de los bancos afectados que sufrieron pérdidas millonarias también se cuentan bancos estatales en Alemania (Henneke, 2010, p. 114)2. Así por ejemplo, el banco del estado federado de Baviera tenía títulos de esa clase por un valor de treinta mil millones de euros (esto equivale a cerca de setenta billones de pesos colombianos) y el banco del estado federado de Sajonia había comprado títulos con un valor total de por lo menos veinte mil millones de euros 囚equivalente a cuarenta y siete billones de pesos colombianos-(Lutter, 2009, p. 790) ${ }^{3}$. El banco del estado federado de Sajonia no pudo soportar estas pérdidas y por lo tanto ya no existe actualmente. Dichos acontecimientos servirán como ocasión para entrar a explicar en detalle los fundamentos jurídicos de los bancos de los estados federados, así como para exponer sus límites y las posibilidades de control a los que está sometida su actividad.

\section{Los bancos de los estados federados}

¿Qué son los bancos de los estados federados? Tienen sus orígenes a comienzos del siglo XX. Con la introducción de los medios de pago sin efectivo se crearon

${ }^{1}$ Lutter, BB 2009, 786 (786); Sachverständigenrat, Das deutsche Finanzsystem, 2008, p. 125.

${ }^{2}$ Henneke, Der Landkreis 2010, 111 (114).

${ }^{3}$ Lutter, BB 2009, 786 (790). 
bancos centrales para los bancos de los municipios de determinadas regiones (Henneke, 2010, p. 180)4. Estos bancos servían como plazas de compensación para las transacciones de pago sin efectivo y para la administración de las reservas de liquidez de los bancos de los municipios que los integraban. Ya en los años veinte iniciaron, además, el negocio de otorgar créditos de corto plazo para optimizar el uso de sus excedentes de caja. Después de la Segunda Guerra Mundial, los recién creados estados federados convirtieron los bancos centrales de los bancos municipales en bancos de los estados federados. Así muchos estados federados tuvieron de esa manera su propio banco principal. Con esto le correspondieron a los bancos de los estados federados las funciones de un banco estatal. Como bancos estatales, se ocupaban de los negocios bancarios del respectivo estado federado y servían de apoyo para sus objetivos económicos. Entre tanto, los bancos de los estados federados están autorizados para gestionar todo tipo de negocios bancarios y conexos. De esta manera se han convertido en bancos comerciales universales, o bien en los así llamados bancos universales, es decir, ellos gestionan todos los negocios de orden bancario para un amplio círculo de clientes. Por esta razón actualmente los bancos de los estados federados entran en directa competencia con los institutos privados de crédito (Schmidt, 1990, p. 512)

Como ejemplo ilustrativo, en este artículo se traerá a colación de vez en cuando el ejemplo del estado federado Baden-Württemberg (que es donde está la ciudad de Konstanz). También este cumple diversas funciones: es el banco principal del estado federado de Baden-Württemberg, funge como banco central de los bancos municipales de los estados de Baden-Württemberg, Renania-Palatinado y Sajonia, y es además banco municipal de la capital del estado federado de Baden-Württemberg. Como los demás bancos de los estados federados, actualmente el banco de Baden-Württemberg (también llamado LBBW) se concibe en primer orden como un banco universal e incluso como un banco de negocios internacionales (LBBW, 2011, p. 39; Möschel, 2001, p. 1.009)6. También la ley sobre el banco del estado federado Baden-Württemberg (también llamada LBWG) le atesta una "libertad negocial completa". El banco dispone de más de doscientas filiales en todo el territorio federal y con más de veinte sucursales en el exterior, se encuentra

\footnotetext{
${ }^{4}$ Henneke, VB1BW 2010, 173 (180).

${ }^{5}$ Schmidt, Öffentliches Wirtschaftsrecht AT, 1990, p. 512.

${ }^{6}$ Informe comercial del LBBW 2011, p. 39; Möschel, WM 2001, 1.009 (1.009).

${ }^{7}$ Ver en $§ 2, \mathrm{I}$ LBWG.
} 
representada en los principales centros financieros del mundo como Londres, Nueva York, y Shanghai; tiene además más de doce mil empleados y presentó a finales del año 2011 un balance de más de trescientos setenta mil millones de euros "equivalente a ochocientos sesenta billones de pesos colombianos- (LBBW, 2011) ${ }^{8}$. Con esto hace parte de los diez institutos de crédito más grandes de Alemania y tiene actividades en todos los campos negociales de un banco moderno.

\section{Disposiciones de derecho constitucional}

En primer lugar hablemos sobre las disposiciones de derecho constitucional: una actividad económica del sector público "y con esto también la gestión de institutos de crédito como los bancos de los estados federados" no es automáticamente inadmisible (Lutter, 2009, p. 789; Ziekow, 2010, Rn. 29)9 . Está, sin embargo, sometida a determinados requisitos constitucionales. Se deben nombrar, por ejemplo, el principio de Estado de Derecho y el Principio Democrático, así como los derechos fundamentales (Schulze-Feilitz, 2012, Rn. 132; Lampert, 2010, p. $1.466)^{10}$. Constitucionalmente se exige en especial la existencia de un fin público para la actividad económica, puesto que el actuar del sector público solo es admisible cuando se persiguen tareas públicas (BVerfG, 1983, p. 107) ${ }^{11}$. Con esto se hace referencia al aseguramiento y promoción del bien común. El bien común es designado, por tal razón como "el fundamento y el límite de la actuación estatal" (Schuppert, 2004, p. 441) ${ }^{12}$. A pesar de que es difícil determinar de manera abstracta para el caso concreto qué actividades estan comprendidas dentro del concepto del bien común, sí es posible constatar qué actividades no cumplen este requisito. La pura actividad productiva, dirigida exclusivamente a la obtención de utilidades que no tiene en cuenta los fines del bien común o que solo lo hace de manera secundaria, es inadmisible (BVerfG, 1983, p. 107) ${ }^{13}$. Según esto, por ejemplo, la adquisición

\footnotetext{
${ }^{8}$ Ver en el informe comercial del LBBW 2011.

${ }^{9}$ Lutter, BB 2009, 786 (789); Ziekow, Öffentliches Wirtschaftsrecht, 2010, § 7, número marginal 29.

${ }^{10}$ Schulze-Fielitz, en: Hoffmann-Riehm/Schmidt-Aßmann/Voßkuhle, GVwR I, 2012, § 12, número marginal 132; Lampert, DVB1 2010, 1466.

${ }^{11}$ BVerfGE 61, 82 (107); Ehlers, Jura 1999, 212 (214); Ruthig/Storr, Öffentliches Wirtschaftsrecht, 2008, § 8, número marginal 699; Ziekow, Öffentliches Wirtschaftsrecht, 2010, § 7, número marginal 29.

${ }^{12}$ Schuppert, GewArch 2004, 441 (441).

${ }^{13}$ BVerfGE 61, 82 (107); Ehlers, Jura 1999, 212 (214).
} 
de participaciones en una compañía productora de tabaco, a causa de una esperada participación en las ganancias, estaría prohibida por las disposiciones del derecho constitucional. La conexión con el bien común como medida para una actividad productiva del Estado también rige sin excepciones para el ámbito de los servicios financieros, es decir, para cuando el Estado opera bancos propios.

\section{Formas jurídicas y organización de los bancos públicos}

Así como para las empresas públicas en general, también para los bancos del sector público existe, en principio, una libertad de elección de las formas de organización. Al Estado le están abiertas no solo las formas jurídicas de derecho público sino también las de derecho privado (Vollmöller, 2007, Rn. 5) ${ }^{14}$. El Estado puede elegir libremente la forma de organización que le resulte más ventajosa para el cumplimiento de una tarea concreta, en tanto que una forma determinada no esté prescrita por ley (Schulze-Fielitz, 2012, Rn. 130) ${ }^{15}$. En la actualidad solo dos bancos de los estados federados en Alemania están organizados como sociedades privadas por acciones. Los demás bancos de los estados federados fueron constituidos como establecimientos de derecho público con personería jurídica. Como tales, pertenecen a los organismos responsables de la administración pública (Laubinger, 2001, p. 642) ${ }^{16}$.

\subsection{El establecimiento de derecho público con personería jurídica como forma jurídica típica}

a. Concepto y esencia del establecimiento público

Bajo un establecimiento de derecho público se entiende un estado de personas o cosas que "se encuentra en poder de un responsable de la administración pública y que [ ] ha sido determinado para servir a un fin público específico" (Mayer, 1924, p. 268 ${ }^{17}$. Se trata inicialmente de una forma de organización de derecho público

${ }^{14}$ Vollmöller, en: Schmidt/Vollmöller, Kompendium Öff.WirtschaftsR, 2007, § 5, número marginal 5.

${ }^{15}$ Schulze-Fielitz, en: Hoffmann-Riehm/Schmidt-Aßmann/Voßkuhle, GVwR I, 2012, § 12, número marginal 130.

${ }^{16}$ Laubinger, in: FS Maurer, 2001, p. 641 (642).

${ }^{17}$ Mayer, Deutsches Verwaltungsrecht, 1924, p. 268. 
(Maurer, 2011, § 23, Rn. 53) ${ }^{18}$, pero también de una forma de actuación estatal (Laubinger, 2001, p. 650) ${ }^{19}$. En lo que respecta a su posición jurídica, el establecimiento puede estar dotado de su propia personería jurídica; esto, sin embargo, no es una condición forzosa. Si bien como establecimiento sin personería jurídica no es autónomo en términos jurídicos, sí lo es en la mayoría de los casos desde el punto de vista de su organización. Como ejemplo típico de establecimientos sin personería jurídica pueden nombrarse las escuelas (Ennuschat, 2012, p. 342) ${ }^{20}$. Por su autonomía jurídica, el establecimiento público con personería jurídica tiene permitido y está obligado a cumplir las funciones que le son asignadas bajo su propia responsabilidad. Es por sí mismo sujeto para la asignación de derechos y obligaciones y debe responder, en principio, por las obligaciones que contraiga (Maurer, 2011, § 23, Rn. 49) 21. Como responsable autónomo de la administración, tiene que ser creado por ley o en virtud de una ley. Así, por ejemplo, el banco del estado federado Baden-Württemberg fue creado expresamente por una ley ${ }^{22}$.

\section{b. Responsables del establecimiento}

El responsable de la administración que constituye el establecimiento es designado como responsable de este. Él determina la organización y las funciones del establecimiento en tanto estas no hayan sido ya establecidas por ley (Maurer, 2011, § 23, Rn. 51) ${ }^{23}$. No obstante, a diferencia de las sociedades de personas y capitales, el responsable del establecimiento no es miembro o socio de este, sino solo el titular jurídico (Schraml, 2011, § 45, Rn. 6) ${ }^{24}$. Por lo general el responsable del establecimiento es una corporación territorial, como por ejemplo la Federación, un estado federado, o un municipio. Varios entes soberanos también pueden ser responsables en conjunto de un establecimiento (Müller, 2004, § 88, Rn. 13) ${ }^{25}$. El

${ }^{18}$ Maurer, Allgemeines Verwaltungsrecht, 2011, § 23, número marginal 53.

${ }^{19}$ Laubinger, en: FS Maurer, 2001, p. 650.

20 Por ejemplo: Ennuschat, DV 2012, 331 (342).

${ }^{21}$ Maurer, Allgemeines Verwaltungsrecht, 2011, § 23, número marginal 49.

22 Gesetz über die Landesbank Baden-Württemberg (LBWG) vom 11. November 1998, GB1. p. 589; zuletzt geändert durch Gesetz zur Änderung des Landesbankgesetzes vom 14 august 2010.

${ }_{23}$ Maurer, Allgemeines Verwaltungsrecht, 2011, § 23, número marginal 51.

${ }^{24}$ Schraml, en: Mann/Püttner, Handbuch der kommunalen Wissenschaft und Praxis Bd. 2, 2011, $\S 45$, número marginal 6 .

${ }_{25}$ Müller, in: Wolff/Bachof/Stober, Verwaltungsrecht Bd. 3, 2004, § 88, número marginal 13. 
establecimiento mismo, por lo tanto, es un miembro de su titular externo, el cual ejerce, en la mayoría de los casos, una influencia constante sobre el establecimiento (Müller, 2004, § 88, Rn. 14) ${ }^{26}$. Así, por ejemplo, los titulares del establecimiento del banco del estado federado Baden-Württemberg son el estado federado del mismo nombre, la ciudad de Stuttgart como la capital estado federado y la asociación de los bancos municipales de Baden-Württemberg ${ }^{27}$. Estos tres titulares del establecimiento son corporaciones de derecho público.

\section{c. Carga del establecimiento y responsabilidad de garantía del titular}

La relación del establecimiento con su titular está marcada por la así llamada “carga del establecimiento”. Esta obliga al titular del establecimiento a conservar la funcionalidad de este durante su existencia, y dado el caso también a compensar déficits que puedan presentarse (Müller, 2004, § 88, Rn. 14; Stern, 2001, p. 816) ${ }^{28}$. La carga del establecimiento es un principio de derecho no escrito del derecho administrativo alemán. De ella viene la expresión según la cual una corporación de derecho público que crea un establecimiento no puede sustraerse a la responsabilidad sobre él (Stern, 2001, p. 818; Kemmler, 2003, p. 103) ${ }^{29}$. Cuando la administración le transfiere una función al establecimiento, le queda siempre a la administración el deber de garantizar las finanzas para el cumplimiento de la función por parte del establecimiento. La carga del establecimiento abarca únicamente la relación interna entre el establecimiento y la corporación que lo constituye (Stern, 2001, p. 816) ${ }^{30}$.

En estrecha conexión con esto, pero siendo algo que debe separarse conceptualmente, se encuentra la responsabilidad de garantía del titular, que al mismo tiempo da un viraje al exterior a la carga del establecimiento. Según esta responsabilidad el titular del establecimiento está obligado a responder por las obligaciones del establecimiento frente a terceros, cuando y en la medida que este no se encuentre en condiciones de satisfacerlas (Maurer, 2011, § 23, Rn. 51) ${ }^{31}$. En comparación con la

\footnotetext{
${ }^{26}$ Müller, in: Wolff/Bachof/Stober, Verwaltungsrecht Bd. 3, 2004, § 88, número marginal 14; ver también: BVerfGE 93, 37.

${ }^{27} \S 4$ LBWG.

${ }^{28}$ Müller, en: Wolff/Bachof/Stober, Verwaltungsrecht Bd. 3, 2004, § 88, número marginal 14; Stern, en: FS Maurer, 2001, p. 815 (816).

${ }^{29}$ Stern, en: FS Maurer, 2001, p. 815 (818); Kemmler, DVB1 2003, 100 (103).

${ }^{30}$ Stern, en: FS Maurer, 2001, p. 815 (816).

${ }^{31}$ Maurer, Allgemeines Verwaltungsrecht, 2011, § 23, número marginal 51.
} 
carga del establecimiento, se trata de una responsabilidad subsidiaria pero ilimitada (Müller, 2004, § 88, Rn. 14 y 125) ${ }^{32}$. Este tipo de responsabilidad es designada como una "especie de aval subsidiario de derecho público" y como una "garantía subsidiaria" 33 . Si el acreedor no puede satisfacer sus créditos con el patrimonio del establecimiento, en virtud de la responsabilidad de garantía del titular le asiste un derecho de satisfacción de sus acreencias frente al responsable-titular de la entidad (FüßER, 2002, 306; Jarass, 2005, p. 942)34. Si, por ejemplo, el banco del estado federado Baden-Württemberg tuviera dificultades para cubrir sus acreencias y por lo tanto no pudiera pagar los créditos tomados por él, el acreedor podría dirigirse directamente al titular del establecimiento, es decir, directamente al estado federado, a la capital Stuttgart o a la asociación de los bancos municipales del estado federado Baden-Württemberg. En lo que se ha podido constatar, la responsabilidad de garantía del titular no ha sido relevante en la práctica, lo que puede ser explicado en virtud de su carácter subsidiario: en los casos dudosos las dificultades en los pagos fueron superadas en el marco de la carga del establecimiento, de manera que hasta ahora nunca ha sido necesario recurrir a la responsabilidad necesaria (Jarass, 2005, p. 941) ${ }^{35}$.

Este modelo de responsabilidad estatal condujo, gracias a la alta seguridad de la liquidez, a ventajas competitivas de los bancos públicos frente a los privados. Se podrían nombrar, por ejemplo, las periódicas calificaciones de las agencias de riesgo internacionales en la mejor categoría "Triple-A" y gracias a ello, costos bajos de refinanciación (Möschel, 2001, p. 1.010; Schulze-Fielitz, 2012, § 12, Rn. 136) ${ }^{36}$. Adicionalmente, los bancos públicos en la forma de establecimientos públicos en la práctica nunca fueron susceptibles de insolvencia. El sistema de responsabilidad que absorbe eventuales pérdidas fue fundamentado, en especial, con la función pública de estos bancos (Müller, 2004, § 88, Rn. 119-132) ${ }^{37}$. A finales de los años 90 el sistema recibió atención de los organismos de protección de la competencia de la comisión europea. Según su opinión, los privilegios de responsabilidad basados en la carga de

${ }^{32}$ Müller, en: Wolff/Bachof/Stober, Verwaltungsrecht Bd.3, 2004, § 88, número marginal 14 y 125.

${ }^{33}$ Por ejemplo: Burgi, en: Erichsen/Ehlers, Allgemeines Verwaltungsrecht, 2010, § 8, número marginal 14; Füßer, ZBB 2002, 300 (306); Jarass, WM 2005, 941 (942); Stern, en: FS Maurer, 2001, p. 815 (818).

${ }^{34}$ Füßer, ZBB 2002, 300 (306); Stern, en: FS Maurer, 2001, p. 815 (823).

${ }^{35}$ Jarass, WM 2005, 941 (941).

${ }^{36}$ Möschel, WM 2001, 1009 (1010); Schulze-Fielitz, en: Hoffmann-Riehm/Schmidt-Aßmann/ Voßkuhle, GVwR I, 2012, § 12, número marginal 136.

${ }^{37}$ Müller, en: Wolff/Bachof/Stober, Verwaltungsrecht Bd. 3, 2004, § 88, número marginal 119 y 132. 
los establecimientos y en la responsabilidad de garantía del titular debían clasificarse como ayudas estatales que son adecuadas para falsear la competencia (Henneke, 2011, § 53, Rn. 205; Quardt, 2002, p. 424) ${ }^{38}$. Puesto que de esa manera se afirmó una vulneración del derecho de la Unión Europea ${ }^{39}$, los representantes del gobierno federal y de los estados federados llegaron a un acuerdo con la comisión europea para distanciarse de este modelo de responsabilidad (Kemmler, 2003, p. 101; Krämer, 2002, p. 37; Wiesel, 2002, p. 290) ${ }^{40}$. Como consecuencia de este pacto se debía abolir completamente a partir del año 2005 la responsabilidad de garantía del titular como garantía subsidiaria. El lugar de la carga del establecimiento fue ocupado por una relación de propiedad normal en la economía de mercado, con la consecuencia de la posibilidad de la insolvencia de los bancos públicos (Müller, 2004, § 88, Rn. 126; Burgi, 2010, § 8, Rn. 14) ${ }^{41}$. Con ello, la responsabilidad de los titulares de los bancos de los estados federados fue limitada a la suma del capital base consagrado en los estatutos (Jarass, 2005, p. 941) ${ }^{42}$. En el caso del banco del estado federado Baden-Württemberg este asciende a cerca de dos mil seiscientos millones de euros, lo que corresponde a una suma superior a seis billones de pesos colombianos.

Por medio de esa modificación del modelo clásico de responsabilidad de los establecimientos públicos se muestra, por una parte, que si bien la carga del establecimiento y la responsabilidad de garantía de del titular constituyen características típicas, no se trata de componentes forzosos de un establecimiento. Por otro lado, se hace claro que el ordenamiento jurídico alemán en ocasiones se ve expuesto a considerables modificaciones forzosas a causa de las exigencias de armonización con el derecho de la Unión Europea.

\section{Organización}

Conforme al derecho constitucional las estructuras de organización de los institutos de crédito de derecho público son influenciadas de manera determinante

\footnotetext{
${ }^{38}$ Henneke, en: Mann/Püttner, Handbuch der kommunalen Wissenschaft und Praxis Bd. 2, 2011, $\S 53^{a}$, número marginal 205; Quardt, EuZW 2002, 424.

${ }^{39}$ Ver en Art. 107, 108 TFUE.

${ }^{40}$ Kemmler, DVB1 2003, 100 (101); Krämer, der Gemeindehaushalt 2002, 37; Wiesel, ZBB 2002, 288 (290)

${ }^{41}$ Müller, en: Wolff/Bachof/Stober, Verwaltungsrecht Bd. 3, 2004, § 88 número marginal 126; Burgi, en: Erichsen/Ehlers,

${ }^{42}$ Jarass, WM 2005, 941 (941).
} 


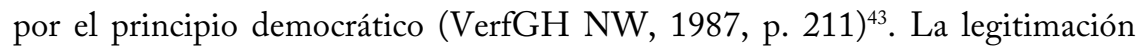
democrática es un mandato de la Ley Fundamental, que procede cuando se ejerce poder público. Con esto se abarca no solo el desempeño de verdaderas competencias soberanas sino también la totalidad de la actividad del sector público (Grzezsick, 2010, Art. 20 Rn. 90) $)^{44}$. Así, el poder público no solo es ejercido cuando, por ejemplo, se expide un acto administrativo, sino también cuando el Estado actúa fiscalmente. Esto significa que también los bancos de los estados federados ejercen poder público cuando participan en el mercado. Por esto también tiene que existir una cadena de legitimación democrática ininterrumpida que parta del pueblo y llegue hasta las estructuras de organización de los bancos de los estados federados (Vollmöller, 2007, § 5, Rn. 53) ${ }^{45}$.

El banco del estado federado Baden-Württemberg cumple este requisito. De manera similar a una sociedad por acciones, está dotado de los tres órganos, asamblea general, junta directiva y consejo de vigilancia ${ }^{46}$. La asamblea general está compuesta exclusivamente por los titulares del establecimiento ya mencionados. La asamblea decide sobre todas las medidas esenciales de conducción de la empresa, por ejemplo, sobre la utilización de las utilidades o la destitución de integrantes del consejo de vigilancia o de la junta directiva. Decide además sobre los estatutos del banco y sus modificaciones ${ }^{47}$. De esa manera, las competencias centrales de dirección y de control se encuentran en poder de los titulares del establecimiento, los cuales están legitimados democráticamente: el estado federado Baden-Württemberg a través de las elecciones al parlamento del estado federado, la ciudad de Stuttgart a través de las elecciones municipales y la asociación de los bancos municipales "puesto que se encuentra bajo la titularidad de los municipios" también de manera mediata por las elecciones municipales. Para lo demás, es decir, la "dirección específica" de los negocios le corresponde al consejo de vigilancia y a la junta directiva. El consejo de vigilancia determina los principios de la política negocial, compone la junta directiva y vigila "junto a la asamblea general" la dirección de los negocios ${ }^{48}$.

\footnotetext{
${ }^{43}$ VerfGH NW, NVwZ 1987, 211.

44 Grzeszick, en: Maunz/Dürig, GG-Kommentar, 2012, Art. 20, número marginal 90 ss.

45 Vollmöller, en: Schmidt/Vollmöller, Kompendium Öff.WirtschaftsR, 2007, § 5, número marginal

${ }^{46}$ Ver en $\S 6$, I LBWG.

47 Ver en $\S 8$, LBWG.

$48 \S 11, \mathrm{LBWG}$.
} 53. 
El consejo está compuesto mayoritariamente por los titulares del establecimiento, con lo cual se asegura su influencia ${ }^{49}$. La junta directiva se encarga del manejo del banco, conduce los negocios y ostenta la representación legal ${ }^{50}$. La junta no puede tomar por sí misma decisiones de gran trascendencia o alcance y, por así decirlo, se encarga solo de los $\$ negocios ordinarios囚. Puesto que además está sometida al control por parte de la asamblea general y del consejo de vigilancia, no se requiere ningúna otra legitimación democrática.

\section{Dudosa vinculación al bien común de los bancos de los estados federados como bancos de negocios}

Cuando los bancos de los estados federados prestan servicios como banco central de los bancos municipales o bajo el encargo del estado federado respectivo, esto contribuye al cumplimiento de fines públicos. La relación con el bien común de estas actividades que ya eran desarrolladas a principios del siglo veinte, por lo general no es cuestionada. Se puede fundamentar con que los bancos de los estados federados prestan servicios financieros frente a los estados federados y por esa vía hacen posible la realización de propósitos públicos — por ejemplo el fomento económico a nivel local- (Lampert, 2010, p. 1.470; Thode, 1994, p. 177; Kirchhof, 2003, p. 161) ${ }^{51}$.

A través de la admisión de negocios con grandes clientes que actúan a nivel internacional y ante todo en el mercado de capitales, son pertinentes las dudas sobre si con las políticas expansivas de esa índole todavía se persigue un propósito público (cfr. Gramlich, 1995, p. 456) ${ }^{52}$. Más bien prevalecen las dudas sobre la vinculación al bien común en este ámbito, en donde los bancos de los estados federados llevan a cabo "negocios bancarios de todo tipo". Con esto se hace referencia en especial a los negocios a título propio con papeles registrados en bolsa. La limitación de la actividad productiva estatal a los propósitos públicos debe proteger

${ }^{49} \mathrm{E}$ l consejo de vigilancia está compuesto por 21 miembros, de estos son elegidos 14 de la asamblea general (§ 9, I LBWG). El consejo de vigilancia necesita una mayoria simple tomar decisiones ( $\$ 11$, III LBWG).

${ }^{50} \S 13, \mathrm{I}$ LBWG.

${ }^{51}$ Lampert, DVB1 2010, 1.466 (1.470); Thode, Kreditwesen 1994, 172 (177); Kirchhoff, en: FS Cox, 2003, p. 161.

${ }^{52}$ Cfr. Gramlich, en: Schmidt, Öffentliches Wirtschaftsrecht Besonderer Teil 1, 1995,p. 456; Lampert, DVB1 2010, 1466; Lutter, BB 2009, 786. 
al sector público de correr riesgos económicos innecesarios y de una posible sobre exigencia económica (Lutter, 2009, p. 789; Storr, 2001, p. 117) ${ }^{53}$. Naturalmente el Estado tiene permitido y debe lograr rendimientos en la persecución de propósitos públicos (Ehlers, 1990, p. 1.091; Lutter, 2009, p. 789) ${ }^{54}$. Sin embargo, esto solo debe constituir un fin accesorio, y no la razón para la existencia de la actividad empresarial del Estado.

Después de las experiencias de la crisis financiera, se puede afirmar que en todo caso la adquisición de títulos valores de alto riesgo no perseguía fin público alguno. En el caso concreto, los bancos de los estados federados se convirtieron de manera indirecta en acreedores de los créditos de propietarios de viviendas en los Estados Unidos. No se puede encontrar un fin público en este contexto. Se trató, más bien, de intereses de obtener ganancias bajo el ocultamiento de los riesgos relacionados con ello (Lutter, 2009, p. 790; Lampert, 2010, p. 1.472)55. Después de la eliminación de la carga de los establecimientos vigente hasta el momento, los bancos se esforzaron por obtener más capital por este medio. Sin embargo, precisamente la actividad económica dirigida a la pura obtención de ganancias, es inadmisible. Para el caso del banco del estado federado de Sajonia, que especuló con ese tipo de títulos con una suma que superó los veinte mil millones de euros, la inadmisibilidad fue constatada con posterioridad por el tribunal constitucional de dicho estado federado (Sächs, 2010, p. 10) ${ }^{56}$. Además es generalmente reconocido que los dineros de los contribuyentes, en principio, justamente no deben ser utilizados para incurrir en tales riesgos (Lutter, 2009, p. 789; Storr, 2001, p. 117) ${ }^{57}$. La expansión de las áreas de negocios de los bancos de los estados federados ${ }^{58}$ en el sentido expuesto es por ello bastante cuestionable desde el punto de vista jurídico (Lampert, 2010, p. 1.472) ${ }^{59}$, y en caso de un negocio a título propio con títulos valores que implicaban grandes riesgos, resulta incluso inconstitucional.

\footnotetext{
${ }^{53}$ Lutter, BB 2009, 786 (789); Storr, Der Staat als Unternehmer, 2001, p. 117.

${ }^{54}$ Eblers, JZ 1990, 1.089 (1.091); Lutter, BB 2009, 786 (789).

${ }_{55}$ Lutter, BB 2009, 786 (790); Lampert, DVB1 2010, 1.466 (1.472).

${ }^{56}$ SächsVerfGH, SächsVB1. 2010, 10.

${ }^{57}$ Lutter, BB 2009, 786 (789); Storr, Der Staat als Unternehmer, 2001, p. 117.

${ }^{58}$ Más Información: Eichhorn, en: FS Cox, 2003, p. 149 (156).

${ }^{59}$ Lampert, DVB1 2010, 1.466 (1.472).
} 


\section{Vigilancia y control}

Para evitar negocios que no están cubiertos por los fines públicos necesarios, y para evitar con ello las pérdidas por negocios riesgosos, se debe indagar por la vigilancia y las posibilidades de control.

\subsection{Vigilancia bancaria y vigilancia estatal "general"}

Al igual que los particulares, los bancos de los estados federados se encuentran bajo la vigilancia bancaria general. Sus objetivos principales consisten en contrarrestar las irregularidades en la actividad bancaria. Se examina si los bancos tienen capital propio y liquidez suficientes y si han instalado mecanismos de control de riesgos razonables. Los preceptos del derecho bancario son medidas exclusivas de control (Fischer, 2011, § 125, Rn. 25) ${ }^{60}$. La vigilancia bancaria no es, con esto, un instrumento eficaz para prevenir negocios que no persiguen un propósito público. Junto a la bancaria, los bancos de los estados federados están sometidos a la vigilancia del estado federado respectivo. Esta se limita a asegurar la juridicidad de la conducción de los negocios y de la administración (Siekmann, 2011, p. 39) ${ }^{61}$. Autoridades de vigilancia jurídica del banco del estado federado Baden-Württemberg son, por ejemplo, el Ministerio de Hacienda y el Ministerio del Interior ${ }^{62}$, es decir, el gobierno del estado federado Baden-Württemberg. Esta vigilancia también debe ser calificada como poco eficaz, puesto que no es independiente: aquí los actores responsables se controlan a sí mismos.

\subsection{Vigilancia y control parlamentario}

Parece más efectivo el control sobre los bancos de los estados federados que es ejercido por los parlamentos, por ejemplo, por medio de las solicitudes de información de cada parlamentario. En su núcleo, estas solicitudes de información se dirigen contra el gobierno y no directamente contra el banco. La praxis muestra que frente a preguntas delicadas el gobierno se escuda en la ignorancia, en el secreto comercial y corporativo o en los derechos de la personalidad de los directivos correspondientes

\footnotetext{
${ }^{60}$ Fischer, en: Schimansky/Bunte/Lwowski, Bankrechts-Handbuch, 2011, § 125, número marginal 25.

${ }^{61}$ Siekmann, Die rechtliche Regulierung öffentlicher Banken in Deutschland, 2011, p. 39.

${ }^{62}$ Ver en $\S 18$, LBWG.
} 
(Siekmann, 2011, p. 45) ${ }^{63}$. No obstante, el gobierno tiene la obligación de procurarse la información necesaria en caso de necesidad (BayVerfGH, 2007, p. 206) ${ }^{64}$. E1 Tribunal Constitucional Federal ha decidido al respecto que el gobierno no puede apoyarse de manera indiscriminada en la ignorancia, la protección de la personalidad o los secretos comerciales para ocultarle al Parlamento situaciones de hecho que sean incómodas para el gobierno (BVerfG, 1999, p. 161) ${ }^{65}$. Sin embargo, en la práctica estatal se recurre cada vez más a designar a los parlamentarios en los órganos de vigilancia de los bancos de los estados federados. Esto pone en peligro no solo la independencia del control parlamentario sino que también conlleva conflictos de intereses (Siekmann, 2011, p. 47; Möschel, 2001, p. 1.011) ${ }^{66}$.

\subsection{Vigilancia y control por los tribunales de cuentas}

En virtud de la Constitución la Federación y los estados federados están sumetidos al control de los tribunales de cuenta ${ }^{67}$. Un tribunal de cuentas es un órgano de control de las finanzas públicas independiente del gobierno respectivo. $\mathrm{Su}$ función consiste en examinar la conducción presupuestal y económica de la administración pública con respecto al cumplimiento de los preceptos jurídicos y de la rentabilidad de sus actuaciones. El control por parte del tribunal de cuentas se extiende a la actividad financiera incluyendo el ámbito de la administración estatal mediata (Krebs, 1984, p. 182) ${ }^{68}$.

Por esta razón puede examinarse, en principio, la actividad de los bancos de los estados federados en cuanto al cumplimiento de su vinculación con el bien común. No obstante, el control por parte de los tribunales de cuentas también presenta déficits: en primer lugar el tribunal de cuentas decide por sí mismo qué y con qué intensidad controla (Krebs, 1984, p. 182) ${ }^{69}$. Si constata violaciones a normas, sus objeciones no provocan consecuencias jurídicas; no tienen efectos jurídicos de

${ }^{63}$ Siekmann, Die rechtliche Regulierung öffentlicher Banken in Deutschland, 2011, p. 45.

${ }^{64}$ BayVerfGH, NVwZ 2007, 204 (206).

${ }^{65}$ BVerfGE 98, 145 (161).

${ }^{66}$ Siekmann, Die rechtliche Regulierung öffentlicher Banken in Deutschland, 2011, p. 47; Möschel, WM 2001, 1.009 (1.011).

${ }^{67}$ Ver en Art. 114 II GG y Art. 83 II Landesverfassung Baden-Württemberg.

${ }^{68} \mathrm{Krebs}$, Kontrolle in staatlichen Entscheidungsprozessen, 1984, p. 182.

${ }^{69} \mathrm{Krebs}$, Kontrolle in staatlichen Entscheidungsprozessen, 1984, p. 182. 
ningún tipo (Krebs, 1984, p. 213) ${ }^{70}$. Por esta razón se conoce al tribunal de cuentas como "caballero sin espada" ${ }^{\text {. }}$

\section{4. ¿Control a través de tribunales por medio de demandas de ciudadanos?}

En este caso los ciudadanos individuales tampoco tienen nada que decir. El individuo no tiene posibilidad de reclamar ante los tribunales vulneraciones de los bancos públicos contra el mandato de vinculación al bien común. El ordenamiento jurídico alemán no conoce una acción general de cumplimiento de normas. En principio el ciudadano solo puede reclamar ante los tribunales la violación de un derecho subjetivo (Maurer, 2011, § 8, Rn. 5) ${ }^{72}$. Se presenta un derecho subjetivo cuando un precepto jurídico está determinado para servir no solo al bien común sino también el interés de un ciudadano particular (Ibler, 2014, Art. 19 IV, Rn. $127)^{73}$. El requisito de la vinculación al bien común sirve, sin embargo, al interés de la generalidad de proteger al Estado de una posible sobre exigencia económica, y no a los intereses de individuos particulares. Así, debe descartarse un control judicial que sea promovido por particulares.

\section{Conclusiones}

Para concluir, se debe exigir que la actividad de los bancos de los estados federados sea reducida a las funciones originalmente concebidas para ellos; por tal razón su actividad debería limitarse de nuevo únicamente a la función como banco central de los bancos municipales. En este contexto también se advierte por una parte de la doctrina que no se necesita más que un solo banco central en todo el territorio federal, y que con ello se deberían abolir todos los bancos de los estados federados salvo uno. Por lo menos los legisladores de los estados federados deberían definir la función pública de dichos bancos con mayor precisión para generar claridad sobre qué actividades ya no están permitidas. Si por el contrario se quisiera continuar siendo banco universal y de negocios internacionales, solo quedaría como alternativa

\footnotetext{
${ }^{70}$ Krebs, Kontrolle in staatlichen Entscheidungsprozessen, 1984, p. 213.

${ }^{71}$ Por ejemplo Gröpl, en: Isensee/Kirchhof, HStR Bd. V, 2007, § 121, número marginal 46.

72 Maurer, Allgemeines Verwaltungsrecht, 2011, § 8, número marginal 5.

${ }^{73}$ Ibler, en: Friauf/Höfling, Berliner Kommentar zum GG, Art. 19 IV, número marginal 127.
} 
la privatización del banco (o las políticas de ánimo de lucro en un campo comercial del banco) bajo una participación mayoritaria de privados, para desprender al banco de su vinculación al bien común. El banco del estado federado Baden-Württemberg ha dado un primer paso en esta dirección, ya que hasta finales del año 2013 deberá ser transformado en una sociedad por acciones bajo el régimen del derecho privado

\section{Referencias}

Burgi. (2010). Allgemeines Verwaltungsrecht. Disponible en http://www.amazon.de/ Allgemeines-Verwaltungsrecht-De-Gruyter-Studium/dp/389949623X.

Ehlers. (1999). Öffentliches Wirtschaftsrecht. Disponible en http://www.juris.de/jportal/prev/ BJLU002840040

Ennuschat. (2012). Cinco preguntas al profesor Dr. Jörg Ennuschat. Disponible en http:// www.fernuni-hagen.de/universitaet/aktuelles/2012/07/11-am-podcast-5-fragen-profennuschat.shtml

Fischer. (2011). Banco Manual de Derecho. 4a Edición 2011. Libro. 94(1), 2929; 94(2), 2917. ISBN 978-3-406-61813-0 CHBeck. Disponible en http://www.beck-shop.de/Schimansky-Bunte-Lwowski-Bankrechts-Handbuch/productview.aspx?product=8641104

Füßer. (2002). Za edna filosofia na fotografiata, Plovdiv. Berlín, Alemania: Horizonti.

Gröpl. (2007). Persom im Ertragsteuerrecht. Berlín, Alemania: Ulrich Palma.

Grzeszick. (2012). Constitución. Disponible en http://www.beck-shop.de/Maunz-DuerigGrundgesetz/productview.aspx?product $=2293$

Henneke. (2011). Manual de la ciencia local y práctica. Disponible en https://portal.dnb. de/opac.htm?method=simpleSearch\&cqlMode=true\&query=idn=550820833

Henneke. (2010). Hebesatzrech tgewahrung, interkommunale gleibbehandlung. Berlín, Alemania: Der Landkreis.

Ibler. (2012). Berliner Kommentar zum Grundgesetz. Disponible en http://www. beck-shop.de/Friauf-Hoefling-Berliner-Kommentar-Grundgesetz/productview. aspx?product=39657\&pac=sem-shop\&adword=google $\% 2$ fFremdtitel_Shop_2\%2 faut $\%$ 3aFriauf_ctr\%3akur_res\%3afremd_p\%3a39657_tit\%3aBerliner-GG\&gclid=CJKTq7C gzMcCFUuRHwod7kgJ3A

Jarass. (2005). Los derechos fundamentales de la UE. Beck, Munich, Alemania. ISBN: 3-406-53215-2.

Kemmler. (2003). Krämer, der Gemeindehaushalt. Berlín, Alemania: Wiesel.

Krämer. (2002). Der Gemeindehaushalt. Berlín, Alemania: Wiesel.

Krebs. (1984). Kontrolle in staatlichen Entscheidungsprozessen. Berlín, Alemania: Nomos. 
Kluth. (2010). Der Landkreis. Berlín, Alemania: Wiesel.

Lampert. (2010). Las acciones de Sears Plunge $10 \%$ como multimillonario Eddie Lampert ingenieros primera beneficio como CEO. Disponible en http://www.forbes.com/profile/ edward-lampert/

Lutter. (2009). BetriebsBerater. Berlín, Alemania: Nodos.

Maurer. (2011). Allgemeines Verwaltungsrecht. Berlín, Alemania: Verlag C. H. Beck.

Mayer. (1924). Deutsches Verwaltungsrecht. Berlín, Alemania: Nodos.

Möschel. (2001). WM. Alemania.

Müller. (2004). \$ 88, en Wolff/Bachof/Stober, Verwaltungsrecht, Band 3. Alemania.

Quardt. (2002). EuZW-Europäische Zeitschrift für Wirtschaftsrecht. Berlín, Alemania: EuZW.

Ruthig, \& Storr. (2008). Öffentliches Wirtschaftsrecht. Berlín, Alemania: Nodos.

Sachverständigenrat. (2008). Das deutsche Finanzsystem. Berlín, Alemania: Nodos.

Schmidt. (1990). Öffentliches Wirtschaftsrecht: Allgemeiner Teil. Berlín, Alemania: Nodos.

Schmidt. (1995). Öffentliches Wirtschaftsrecht Besonderer Teil I. Munich, Alemania: Schmidt, Reine.

Schoch. (2010). Der Landkreis. Munich, Alemania: Springer.

Schraml. (2011). Handbuch der kommunalen Wissenschaft und Praxis, Band 2. En Mann/ Püttner. Hamburgo, Alemania.

Schulze-Fielitz. (2012). Kommentar: Hoffmann-Riehm, Schmidt-Aßmann E'Voßkuble. Berlín, Alemania: GVwR.

Schuppert. (2004). GewArch. Berlín, Alemania : Nodos.

Siekman. (2011). Die rechtliche Regulierung öffentlicher Banken in Deutschland. Berlín, Alemania: GVwR.

Storr. (2001). Der Staat als Unternebmer. Berlín, Alemania: GVwR.

Thode. (1994). Kreditwesen. Berlín, Alemania: GVwR.

Vollmöller. (2007). Kompendium öfentliches Wirtschaftsrechts. Hamburgo, Alemania: Schmidt \& Vollmöller.

Wiesel. (2002). ZBB. Berlín, Alemania: GVwR.

Ziekow. (2010). Öffentliches Wirtschaftsrecht. Berlín, Alemania: GVwR. 